\title{
Lumbosacral agenesis: management and embryological implications
}

\author{
R. J. IGNELZI ${ }^{1}$ AND R. A. W. LEHMAN \\ From the Department of Neurosurgery, University of Colorado Medical Center, \\ Denver, Colorado, U.S.A.
}

SYNOPSIS Rectal biopsy in a case of lumbosacral agenesis showed the presence of autonomic nerve elements normally supplied by spinal levels distal to the agenesis. Certain implications are suggested regarding the embryogenesis of this condition from data about the development of neural, bony, and muscular elements. Recommendations regarding management are given.

Total absence of the spine below the twelfth thoracic vertebra is a rare condition. It represents an extreme form of those dysraphic states termed caudal dysplasia. The patient reported here is the fourteenth case of this anomaly in the world literature. In addition, there are more numerous reports of cases with lesser degrees of caudal dysplasia. The most common of these is sacral agenesis in which the

1 Reprint requests: Dr R. J. Ignelzi, Neurosurgery Section, V. A. Hospital, 3350 La Jolla Village Drive, San Diego, Calif. 92161, U.S.A. anomaly is largely limited to the spine distal to the lumbar region. In none of the cases has an overlying dermal abnormality been described, and attempts to reconstruct the embryogenesis of this condition have been few (Russell and Aitken, 1963; Price et al., 1970).

\section{CASE REPORT}

R.H. was born at full term to a 24 year old diabetic mother in her first pregnancy who had mild preeclampsia. Delivery was uncomplicated. The mother
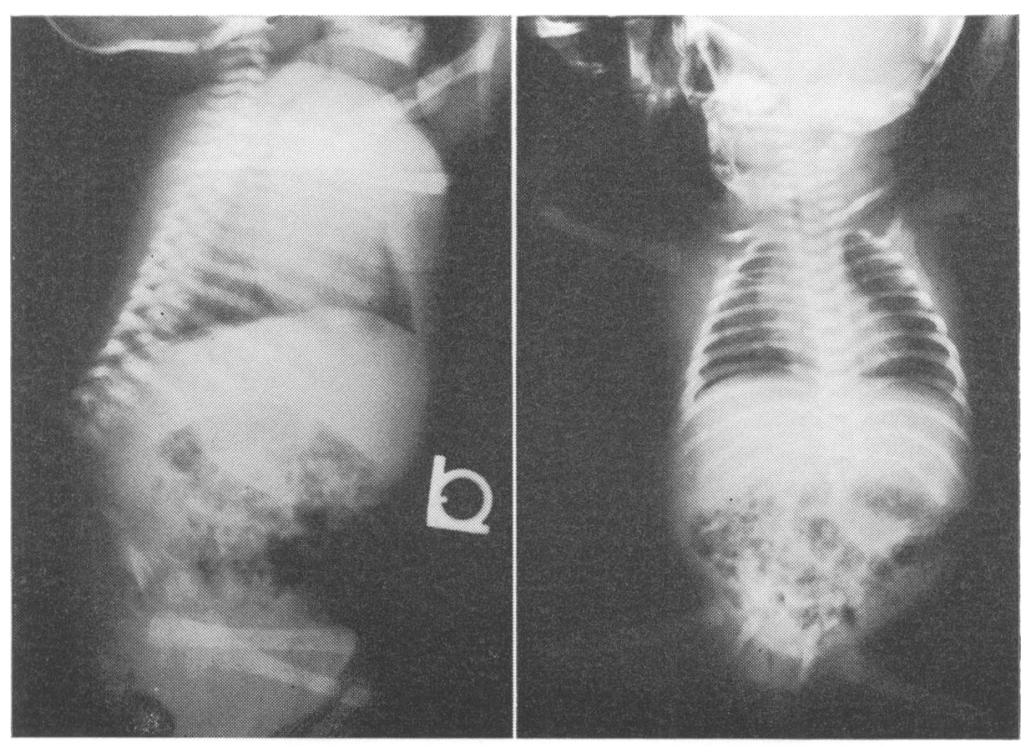

FIG. 1. Anteroposterior and lateral radiography of patient. The spine ends at $T_{12}$ vertebra and there is no sacrum. 
had been taking 30 units of NPH insulin per day during the last four years. She had not tested her urine and had not been followed medically since the initial diagnosis. The mother's maternal grandmother had adult-onset diabetes, but there was no other history of diabetes or congenital anomalies in the family.

The infant was seen at 10 days of age. Head circumference was normal and abnormalities were limited to the lumbosacral area and lower extremities. There was a prominence of the spine at $\mathrm{T} 12$ vertebra. At the most distal extent of this was a raised area, $4 \mathrm{~cm}$ in diameter with a central dimple suggesting the possibility of a dermal sinus tract. The spine was not palpable caudal to this level. The lower extremities maintained a frog leg position and there was webbing of both popliteal fossae with the feet in calcaneus position. Leg mass decreased markedly from proximal to distal. Both lower extremities were floppy with no motor function or reflexes. Several observers were certain that pain perception was present below the waist as judged by the child's facial expression and cries upon application of a pin to the lower abdomen and extremities. Upper abdominal reflexes were intact, but the lower ones were absent. There was no anal reflex or tone. Radiological examination disclosed a narrow pelvis with the ilia articulating amphiarthrodially and complete absence of the lumbar, sacral, and coccygeal spine (Fig. 1). The bones of the lower extremities appeared normal except for calcaneus deformity of both feet. A voiding cystourethrogram demonstrated right urethal reflex and a suggestion of a horseshoe kidney. Electromyography revealed no evidence of muscle function in the lower extremities.
To deal with the possible cutaneous sinus tract and to evaluate the distal spinal canal, exploration was undertaken at 2 months of age. The dermal tract was found to extend only a few millimetres subcu- $\hat{0}$ taneously and terminated before the poorly de- $T$ veloped dorsal fascia. The dural sac was narrow and ended abruptly at T12 vertebra. There was no muscle, vertebra, or nerve visible distal to this point. Only fatty tissue was apparent posterior to the peritoneum. It was elected not to enter the dural sac. A biopsy of paraspinous muscle revealed immature $\bar{T}$ but probably normal muscle. An attempt to biopsy 음 muscle of the left thigh disclosed only fat despite dissection down to the femur. A rectal biopsy contained smooth muscle as well as nerve fibres, plexus, and ganglion cells of normal morphology and number (Fig. 2). Follow-up at 11 months of age revealed no change in function of the lower extremities.

\section{DISCUSSION}

Cases with total lumbosacral agenesis are quite. stereotyped. Frantz and Aitken (1967) re-ported three cases and reviewed those previousl reported in the literature (Russell and Aitken 1 1963). In four of the seven cases reviewe $\frac{1}{2}$ bilateral amputations were performed and the surgical specimens studied. They found no muscle tissue in the specimens examined, although the bony and vascular structures appeares. normal. In those reports in which information provided, the cord was noted to terminate at the level of the last intact vertebra. For this reason, Frantz and Aitken (1967) suggested that

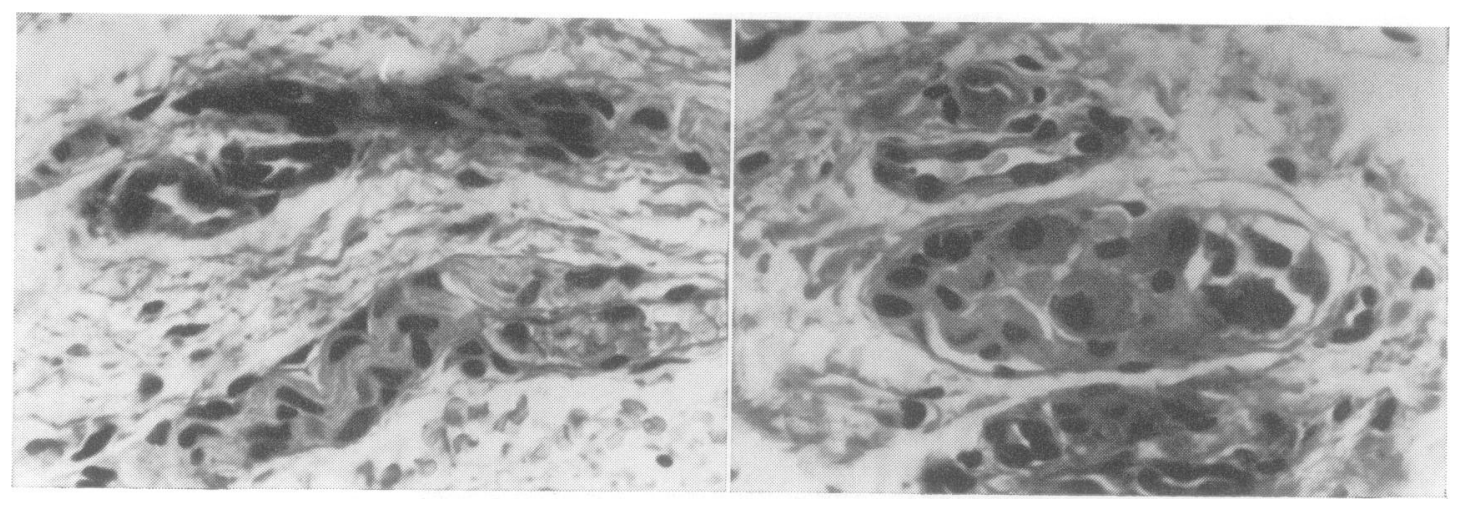

FIG. 2. Rectal biopsy stained with haematoxylin and eosin $(\times 500)$ : (a) normal nerve fibres, (b) a normal parasympathetic ganglion. 
cases with total absence of the lumbosacral spine should have bilateral subtrochanteric amputations of the useless extremities and be fitted with pelvic thoracic buckets with Canadian type hip joints and hinged knee joints for sitting. Followup cystometrograms are recommended at six months to yearly intervals and urinary diversion is often required. Mental function is usually preserved so that early aggressive management is warranted.

Observation of the present case has prompted us to make certain deductions regarding the embryogenesis of this disorder. In the human embryo, differentiation of the caudal neural tube and spine occurs between four and seven weeks of gestation (Arey, 1965). Cases of lumbosacral agenesis have common clinical characteristics suggesting a reproducible embryological defect involving nerve, spinal column, and muscle occurring at or before this period. Experimental studies show that in order for neurulation to occur, both an intact neural plate and mesenchymal substratum are necessary (Kallen, 1968). Detwiler and Holtzer (1954) showed that the amphibian vertebral column is induced in part by the spinal cord. This same phenomenon has been demonstrated in other vertebrates (Hunt, 1932). If a portion of the neural tube is extirpated and the notochord left intact, vertebral bodies develop but vertebral arches do not. If the notochord is removed but the neural tube is preserved, vertebral arches develop without distinct vertebral bodies. Holtzer (1963) concluded that this inductive capacity is restricted to the ventral (motor) region of the spinal cord and notochord sheath. These observations suggest that lack of vertebrae in cases of lumbosacral agenesis might be secondary to non-development of the lower portions of the spinal cord and notochord.

The sensory function apparent in the lower extremities of our case could be explained on the basis of fairly normal segmental development of neural crest tissue in spite of the lack of portions of the neural tube at the level of agenesis. Thus, dorsal root ganglia would develop and presumably connect with the intact spinal cord providing sensory function as observed in our case. This hypothesis is further borne out by the presence of normal ganglion cells with normal nerve fibres in the walls of the rectum. In normal individuals, these rectal ganglion cells are innervated from neurones in the intermediolateral cell column of the spinal cord over the third, fourth, and fifth sacral segments and presumably owe their embryological origins to neural crest tissue at these same levels (Yntema and Hammond, 1955). It is believed that differentiation of the neural crest is uninfluenced by neurulation (Källén, 1968). Thus, it would seem that neural crest derivatives corresponding to the segments of agenesis usually develop, whereas ventral spinal cord elements, if not the entire spinal cord at the level corresponding to the vertebral agenesis, fail to develop.

Not only a segmental lack of vertebrae but also of muscle occurs in this condition. This, too, may be secondary to failure of the spinal cord to develop. Hunt (1932) noted that development and maintenance of differentiating muscle in chicken limb buds is dependent upon a trophic influence of the nervous system. It is of interest in this regard that cases with varying degrees of caudal dysplasia display a correspondence between the point at which the nervous system ends and the point at which the bony and muscular absence occurs (Alexander and Nashold, 1956; Russell and Aitken, 1963).

Our patient had a dermal dimple with a suggestion of a fibrous tract extending beneath it in the skin at the most distal portion of the vertebral column. Whether this represented a residuum of the neuropore and therefore a visible remnant indicating the most distal extent of the neural tube during fetal development is uncertain. There was no connection between the dimple and the spinal canal. One might even speculate that this dimple may actually have been at a sclerotomal level just below the last vertebral level and consequently failed to develop along with other tissues in this region. This would imply that dermal sinus tracts do not occur within an area of spinal agenesis.

In all reported cases there were also congenital urological abnormalities, most commonly a horseshoe shaped kidney. The fact that urogenital primordia differentiate at the same time as the caudal neural tube (Arey, 1965) strongly suggests a single aetiological factor affecting the embryo at a certain point in its development leading to the deformities seen with the syndrome.

Of the possible aetiological factors, heredity 
could be implicated in only one instance of lumbosacral agenesis (Frantz and Aitken, 1967) and none of the 60 reported cases of sacral agenesis. In the cases of sacral agenesis, $16 \%$ of the infants had a maternal history of diabetes (Passarge and Lenz, 1966). Our case of lumbosacral agenesis and one of Frantz and Aitken's were born to diabetic mothers. It is therefore noteworthy that Landauer (1958) was able to produce defective development of the tail skeleton in chickens by the injection of insulin. On the other hand, this syndrome occurs in only about $1 \%$ of infants born to diabetic mothers (Passarge and Lenz, 1966). What role insulin or the diabetic state plays in the pathogenesis of this condition is uncertain, but the relationship seems more than a casual one.

The authors would like to express their appreciation to Dr Michael Norenberg of our neuropathology division for his help in reviewing the pathological specimens. This investigation was supported by National Institutes of Health Training Grant, NS-05564.

\section{REFERENCES}

Alexander, E., Jr, and Nashold, B. S., Jr (1956). Agenesis of the sacrococcygeal region. Journal of Neurosurgery, 13, 507-513.
Arey, L. B. (1965). Developmental Anatomy, 7th edn. Saunders: Philadelphia.

Detwiler, S. R., and Holtzer, H. (1954). The inductive and formative influence of the spinal cord upon the vertebral column. Bulletin of the Hospital for Joint Diseases, 15, 114 123.

Frantz, C. H., and Aitken, G. T. (1967). Complete absence of the lumbar spine and sacrum. Journal of Bone and Joint Surgery, 49-A, 1531-1540.

Holtzer, H. (1963). Comments on induction during cell differentiation. Induktion und Morphogenese. Springer: Berlin.

Hunt, E. A. (1932). The differentiation of chick limb buds in chorio-allantoic grafts, with special reference to the muscles. Journal of Experimental Zoology, 62, 57-91.

Källén, B. (1968). Early embryogenesis of the central nervous system with special reference to closure defects. Developmental Medicine and Child Neurology, Suppl. 16, 44-53.

Landauer, W. (1928). The morphology of intermediate rumplessness in fowl, with remarks concerning hereditary and accidental rumplessness. Journal of Heredity, 19, 453 467.

Passarge, E., and Lenz, W. (1966). Syndrome of caudal regression in infants of diabetic mothers: observations of further cases. Pediatrics, 37, 672-675.

Price, D. E., Dooling, E. C., and Richardson, E. P., Jr (197098 Caudal dysplasia (caudal regression syndrome). Archiveळ̄ of Neurology, 23, 212-220.

Russell, H. E., and Aitken, G. T. (1963). Congenital absenceo of the sacrum and lumbar vertebrae with prosthetiof $N$ management. Journal of Bone and Joint Surgery, 45-A, 501亩 $\omega$ 508.

Yntema, C. L., and Hammond, W. S. (1955). Experiments or the origin and development of sacral autonomic nerves ita the chick embryo. Journal of Experimental Zoology, 129 375-413. 